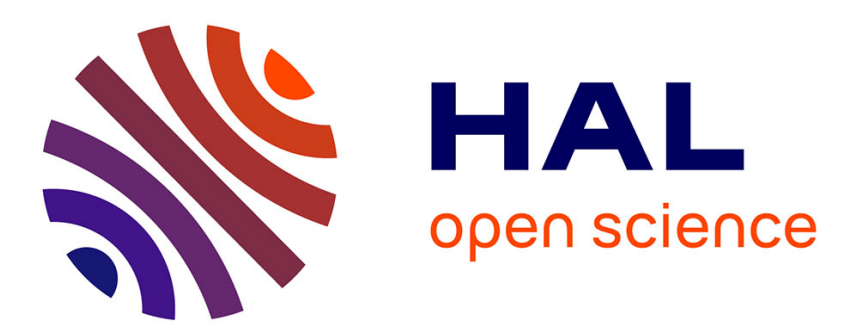

\title{
Synthesis of 26-methyl cholestane and identification of cryostanes in mid- Neoproterozoic sediments
}

\author{
Pierre Adam, Philippe Schaeffer, Jochen J Brocks
}

\section{To cite this version:}

Pierre Adam, Philippe Schaeffer, Jochen J Brocks. Synthesis of 26-methyl cholestane and identification of cryostanes in mid- Neoproterozoic sediments. Organic Geochemistry, 2018, 115, pp.246-249. 10.1016/j.orggeochem.2017.11.006 . hal-02317658

\section{HAL Id: hal-02317658 \\ https://hal.science/hal-02317658}

Submitted on 16 Oct 2019

HAL is a multi-disciplinary open access archive for the deposit and dissemination of scientific research documents, whether they are published or not. The documents may come from teaching and research institutions in France or abroad, or from public or private research centers.
L'archive ouverte pluridisciplinaire HAL, est destinée au dépôt et à la diffusion de documents scientifiques de niveau recherche, publiés ou non, émanant des établissements d'enseignement et de recherche français ou étrangers, des laboratoires publics ou privés. 


\section{Version non révisée}

1 Synthesis of 26-methyl cholestane and identification of cryostanes in mid-

2 Neoproterozoic sediments

4 Pierre Adam, ${ }^{a *}$ Philippe Schaeffer, ${ }^{a}$ Jochen J. Brocks ${ }^{b}$

${ }^{a}$ Université de Strasbourg, CNRS, Institut de Chimie de Strasbourg UMR 7177, F67000 Strasbourg, France

${ }^{b}$ Research School of Earth Sciences, The Australian National University, Canberra ACT 2601, Australia.

* Corresponding author: Tel: +33 (0)3 68852804 .

E-mail address: padam@unistra.fr (Pierre Adam).

\section{Abstract}

The biomarker distributions of mid-Neoproterozoic sediments (800 and 717 million years) from various locations are characterized by the occurrence, besides cholestane isomers, of a novel series of $\mathrm{C}_{28}$ steranes whereas classical C-24 alkylated steranes are absent. These unusual $\mathrm{C}_{28}$ steranes, named cryostanes, seem to be restricted to pre-Snowball Earth sediments. We report here the conclusive identification of cryostanes as 26-methyl cholestanes based on comparison of chromatographic behavior and mass spectrum of the last eluting cryostane isomer with those of a 26 -methyl $5 \alpha(\mathrm{H}), 14 \alpha(\mathrm{H}), 17 \alpha(\mathrm{H}), 20 R$-cholestane standard obtained by synthesis. Sterols methylated at C-26 seem to be restricted to some demosponges, and based on molecular clock estimates, demosponges may have emerged in the time interval 800 to $700 \mathrm{Ma}$. A sponge origin of cryostanes is thus conceivable, making cryostanes the oldest molecular markers for animals. However, other biological sources need to be explored, including the large variety of eukaryotic protists. 


\section{Version non révisée}

29 Key words : mid-Neoproterozoic, Snowball Earth, 26-Methyl cholestane, Synthesis,

30 Cryostanes, Sponges

\section{$31 \quad$ 1. Introduction}

32 The biomarker distributions of mid-Neoproterozoic sediments (800 and 650 million

33 years, Ma) from locations across supercontinent Rodinia are characterized by a 34 unique sterane pseudohomologue distribution with a cholestane predominance approaching 100\% and, in some sediment extracts, traces of ergostane and of a novel series of $\mathrm{C}_{28}$ steranes. By contrast, isomers of stigmastane, 24- $n$-propyl- and 24-isopropyl cholestanes as well as dinosteranes were not detected in the 800 to $650 \mathrm{Ma}$ old sediments (Brocks et al. 2016; 2017). The unique sterane distribution attests to an ecological state of mid-Neoproterozoic eukaryotes that was still distinct from Ediacaran (635 to $541 \mathrm{Ma}$ ) and younger ecosystems (Brocks et al., 2016). The name "cryostanes" was ascribed to the unusual new $\mathrm{C}_{28}$ steranes which are currently restricted to pre-Snowball Earth sediments (>717 Ma). Based on considerations related to their behavior upon gas chromatographic analysis, cryostanes have been postulated to correspond to sterane isomers having a C-26 methylated side-chain (Brocks et al., 2016). We report here the conclusive identification of cryostanes based on comparison of chromatographic behavior and mass spectrum of the last eluting cryostane isomer with those of a 26-methyl $5 \alpha(\mathrm{H}), 14 \alpha(\mathrm{H}), 17 \alpha(\mathrm{H}), 20 R$-cholestane (noted $\quad 26$-methyl $\quad \alpha \alpha \alpha R$-cholestane) $\mathbf{1}$ standard prepared by synthesis.

\section{Experimental}

\subsection{Synthesis of 26-methyl $\alpha \alpha \alpha R$-cholestane 1}

\subsubsection{Cholestan-26-al 3}




\section{Version non révisée}

An epimeric mixture of $25(R)+25(S)$ cholestan-26-ol $2(8.1 \mathrm{mg})$ was reacted with pyridinium dichromate (PDC; $62 \mathrm{mg})$ in dry $\mathrm{CH}_{2} \mathrm{Cl}_{2}(15 \mathrm{ml})$ at room temperature under vigorous stirring. After $90 \mathrm{~min}$, additional PDC (32 mg) was introduced and the reaction stirred for further $2 \mathrm{~h}$. The mixture was filtered on a small silica gel column to remove the reagent, the solvent was evaporated under reduced pressure, and chromatographed on a silica gel column using $\mathrm{CH}_{2} \mathrm{Cl}_{2}$ as eluent, yielding cholestan-26-al $3(7.0 \mathrm{mg} ; 88 \%)$ as a 1/1 C-25 $(R+S)$ epimeric mixture not separated by GC, but distinguable by NMR. GC-MS (EI, $70 \mathrm{eV}$ ); $m / z$ (relative intensity) 386 (M+, 18\%), 371 (26), 358 (3), 276 (6), 217 (100), 203 (19), 149 (53), 95 (38). ${ }^{1} \mathrm{H}-\mathrm{NMR}$ (500 MHz; $\left.\mathrm{CDCl}_{3}\right): 0.620(3 \mathrm{H}, \mathrm{s}, \mathrm{H}-18), 0.751(3 \mathrm{H}, \mathrm{s}, \mathrm{H}-19), 0.874(3 \mathrm{H}, \mathrm{d}, J=6.5$ Hz, H-21), 1.065 (3H, d, $J=6.5 \mathrm{~Hz}, \mathrm{H}-27)^{\mathrm{a}}, 1.067(3 \mathrm{H}, \mathrm{d}, J=6.5 \mathrm{~Hz}, \mathrm{H}-27)^{\mathrm{a}}, 1.77$ $(1 \mathrm{H}, \mathrm{m}), 1.92(1 \mathrm{H}, \mathrm{td}, J=3.5 \mathrm{~Hz}, J=12.0 \mathrm{~Hz}), 2.31(1 \mathrm{H}, \mathrm{m}, \mathrm{H}-25), 9.589(1 \mathrm{H}, \mathrm{d}, J$ $=2.0 \mathrm{~Hz}, \mathrm{H}-26)^{\mathrm{b}}, 9.592(1 \mathrm{H}, \mathrm{d}, J=2.0 \mathrm{~Hz}, \mathrm{H}-26)^{\mathrm{b}} .{ }^{13} \mathrm{C}-\mathrm{NMR}\left(125 \mathrm{MHz} ; \mathrm{CDCl}_{3}\right): 12.3$, $12.4,13.6^{*}, 18.8^{*}, 21.0,22.4,23.7^{*}, 24.4,27.1,28.5,29.3,29.3,31.2^{*}, 32.4,35.6$, $35.9^{*}, 36.2^{*}, 36.5,38.9,40.3,42.8,46.6^{*}, 47.3,55.0,56.4,56.8,205.7 .^{*}$

a, b chemical shifts with the same superscript label correspond to the signal of the same proton from the two epimers at C-25.

* splitted signals in the ${ }^{13} \mathrm{C}$-NMR spectrum reflecting the presence of two epimers at C-25.

\subsubsection{6-Methylene-cholestane 4 (epimeric mixture at C-25)}

An aliquot $(500 \mu \mathrm{l})$ of a solution of triphenylphosphine $\left(\mathrm{PPh}_{3} ; 295 \mathrm{mg}\right)$, isopropanol (75 $\mu \mathrm{l})$ and tris(triphenylphosphine)rhodium(I) chloride (Wilkinson's catalyst; 31 $\mathrm{mg}$ ) in tetrahydrofuran (THF; $10 \mathrm{ml})$ and trimethylsilyldiazomethane $\left(\mathrm{TMSCHN}_{2}\right.$; $2 \mathrm{~N}$ in diethylether, $80 \mu \mathrm{l}$ ) were added, successively, on a mixture containing cholestan-26-al 3 (2.4 mg) and 16-oxo-methylhexadecanoate (6.5 mg). After $45 \mathrm{~min}$, the color of the reaction mixture turned from yellow to red with the formation of 


\section{Version non révisée}

$\mathrm{N}_{2}$ bubbles. After a further $60 \mathrm{~min}$, the excess of $\mathrm{TMSCHN}_{2}$ was eliminated using a few drops of trifluoroacetic acid in $\mathrm{CH}_{2} \mathrm{Cl}_{2}(10 \%$, v/v). The solvent was removed under reduced pressure and 26-methylene-cholestane 4 (1.5 $\mathrm{mg}, 62 \%)$ was recovered from the crude mixture by silica gel column chromatography using cyclohexane as eluent. GC-MS (EI, $70 \mathrm{eV}) ; \mathrm{m} / z$ (relative intensity) $384\left(\mathrm{M}^{+}, 26 \%\right.$ ), 369 (29), 274 (7), 257 (26), 217 (100), 203 (22), 149 (57), 95 (53). ${ }^{1} \mathrm{H}-\mathrm{NMR}$ (500 MHz; $\left.\mathrm{CDCl}_{3}\right): 0.619$ (3H, s, H-18), $0.752(3 \mathrm{H}, \mathrm{s}, \mathrm{H}-19), 0.868(3 \mathrm{H}, \mathrm{d}, J=6.5 \mathrm{~Hz}, \mathrm{H}-21)^{\mathrm{a}}$, $0.870(3 \mathrm{H}, \mathrm{d}, J=6.5 \mathrm{~Hz}, \mathrm{H}-21)^{\mathrm{a}}, 0.952(3 \mathrm{H}, \mathrm{d}, J=7.0 \mathrm{~Hz}, \mathrm{H}-27)^{\mathrm{b}}, 0.953(3 \mathrm{H}, \mathrm{d}, J=$ $7.0 \mathrm{~Hz}, \mathrm{H}-27)^{\mathrm{b}}, 1.77(1 \mathrm{H}, \mathrm{m}), 1.93(1 \mathrm{H}, \mathrm{td}, J=3.5 \mathrm{~Hz}, J=12.0 \mathrm{~Hz}), 2.08(1 \mathrm{H}, \mathrm{m}, \mathrm{H}-$ 25), $4.88(1 \mathrm{H}, \mathrm{d}, J=10.5 \mathrm{~Hz}, \mathrm{H}-28 \mathrm{a}), 4.92(1 \mathrm{H}, \mathrm{d}, J=16.0 \mathrm{~Hz}, \mathrm{H}-28 \mathrm{~b}), 5.660(1 \mathrm{H}$, ddd, $J=7.0 \mathrm{~Hz} J=10.5 \mathrm{~Hz}, J=16.0 \mathrm{~Hz}, \mathrm{H}-26)^{\mathrm{c}}, 5.665(1 \mathrm{H}, \mathrm{ddd}, J=7.0 \mathrm{~Hz} J=$ $10.5 \mathrm{~Hz}, J=16.0 \mathrm{~Hz}, \mathrm{H}-26)^{c} .{ }^{13} \mathrm{C}-\mathrm{NMR}\left(125 \mathrm{MHz} ; \mathrm{CDCl}_{3}\right): 12.3,12.5,18.9,20.4^{*}$; 21.0, 22.4 $23.9,24.4,27.1,28.5,29.3,29.3,32.4,35.8,36.0 *$, 36.2, 36.5, 37.4, 38.0*, $38.9,40.3,42.8,47.3,55.0,56.5,56.9,112.4^{*}, 145.4^{*}$

a, b, c chemical shifts with the same superscript label correspond to the signal of the same proton from the two epimers at C-25.

* splitted signals in the ${ }^{13} \mathrm{C}$-NMR spectrum reflecting the presence of two epimers at C-25.

\subsubsection{6-Methyl $\alpha \alpha \alpha R$-cholestane 1 (epimeric mixture at C-25)}

$\mathrm{PtO}_{2}$ (ca. $10 \mathrm{mg}$ ) was added to an aliquot of 26 -methylene-cholestane $(0.8 \mathrm{mg})$ dissolved in EtOAc $(3 \mathrm{ml})$. After stirring under $\mathrm{H}_{2}$ atmosphere for $90 \mathrm{~min}$, the mixture was put under $\mathrm{N}_{2}$ atmosphere, and the catalyst was filtered off and washed with $\mathrm{CH}_{2} \mathrm{Cl}_{2}$. 26-Me $\alpha \alpha \alpha \mathrm{R}$-cholestane 1 was obtained in quantitative yield. GC-MS (EI, 70 eV); m/z (relative intensity) $386\left(\mathrm{M}^{+}, 17 \%\right), 371$ (32), 276 (11), 217 (100), 203 (20), 149 (42), 95 (17). ${ }^{1} \mathrm{H}-\mathrm{NMR}$ (500 MHz; $\left.\mathrm{CDCl}_{3}\right)$ : 0.623 (3H, s, H-18), $0.753(3 \mathrm{H}, \mathrm{s}, \mathrm{H}-19), 0.816(3 \mathrm{H}, \mathrm{d}, J=6.5 \mathrm{~Hz}, \mathrm{H}-27)^{\mathrm{a}}, 0.820(3 \mathrm{H}, \mathrm{d}, J=6.5 \mathrm{~Hz}, \mathrm{H}-$ 


\section{Version non révisée}

27) $)^{\mathrm{a}}, 0.846(3 \mathrm{H}, \mathrm{t}, J=7.0 \mathrm{~Hz}, \mathrm{H}-28), 0.878(3 \mathrm{H}, \mathrm{d}, J=6.5 \mathrm{~Hz}, \mathrm{H}-21), 1.78(1 \mathrm{H}, \mathrm{m})$, $1.93(1 \mathrm{H}, \mathrm{td}, J=3.5 \mathrm{~Hz}, J=12.0 \mathrm{~Hz}) .{ }^{13} \mathrm{C}-\mathrm{NMR}\left(125 \mathrm{MHz} ; \mathrm{CDCl}_{3}\right): 11.6 * 12.3$, $12.5,14.3,18.9^{*}, 19.5^{*}, 21.0,22.4,23.8^{*}, 24.4,27.1,28.5,29.3^{*}, 29.6,29.9,32.4$, $34.7^{*}, 35.8,36.1,36.5^{*}, 37.4^{*}, 38.9,40.4,42.8^{*}, 47.3,55.0,56.5^{*}, 56.9$.

a chemical shifts with the same superscript label correspond to the signal of the same proton from the two epimers at C-25.

* splitted signals in the ${ }^{13} \mathrm{C}$-NMR spectrum reflecting the presence of two epimers at C-25.

\subsection{Coinjection of 26-methyl $\alpha \alpha \alpha R$-cholestane}

A coinjection experiment of 26-methyl $\alpha \alpha \alpha$ R-cholestane $\mathbf{1}$ and a bitumen containing cryostane was performed on two gas chromatographic columns. The bitumen was extracted from black shale (sample 10J093) of the 740 Ma old Chuar Group collected in the Grand Canyon 1544 meters above the base of the group. Details of the geology and sampling locality are given in Brocks et al. (2016). Any surficial contaminants were removed from the rock sample using the microablation protocol, and bitumen was extracted and fractionated according to procedures outlined by Jarrett et al. (2013).

\subsection{Analytical methods}

\subsubsection{GC-MS}

GC-MS of synthetic products was carried out with a Thermo Scientific Trace Ultra gas chromatograph coupled to a Thermo Scientific TSQ Quantum mass spectrometer equipped with an autosampler Tri Plus and a programmed temperature vaporizing (PTV) injector. The temperature of the source was set at $220{ }^{\circ} \mathrm{C}$. The mass spectrometer was operating in the electron impact (EI) mode at $70 \mathrm{eV}$ and scanning $\mathrm{m} / z 50$ to 700 . Gas chromatographic separations were performed on a HP5-MS column (30 m x $0.25 \mathrm{~mm}$; $0.1 \mu \mathrm{m}$ film thickness) using He 


\section{Version non révisée}

131 as carrier gas. Temperature program: $70{ }^{\circ} \mathrm{C}-200{ }^{\circ} \mathrm{C}\left(10^{\circ} \mathrm{C} \mathrm{min}-1\right), 200{ }^{\circ} \mathrm{C}-300{ }^{\circ} \mathrm{C}(4$

$132{ }^{\circ} \mathrm{C} \min ^{-1}$ ), isothermal at $300{ }^{\circ} \mathrm{C}$ for $40 \mathrm{~min}$. For the co-injection experiments, GC-

133 MS was carried out on an Agilent 6890 gas chromatograph coupled to a Micromass

134 Autospec Premier double sector mass spectrometer (Waters, USA). Detailed MS

135 operating conditions are given in Jarrett et al. (2013). For the co-injection

136 experiments, a $60 \mathrm{~m}$ DB-5 MS (0.25 mm i.d., $0.25 \mu \mathrm{m}$ film thickness, Agilent JW

137 Scientific, USA) and a $60 \mathrm{~m}$ DB-1 MS (0.25 mm i.d., $0.25 \mu \mathrm{m}$ film thickness, Agilent

138 JW Scientific, USA) capillary columns were used with helium as carrier gas

139 (constant flow of $1 \mathrm{ml} / \mathrm{min}$ ). Samples were injected in splitless mode into a Gerstel

$140 \mathrm{PTV}$ injector at $60^{\circ} \mathrm{C}$ (held for $0.1 \mathrm{~min}$ ) and heated at $260^{\circ} \mathrm{C} / \mathrm{min}$ to $300^{\circ} \mathrm{C}$. The $\mathrm{GC}$

141 oven was programmed from $60^{\circ} \mathrm{C}$ (held for $4 \mathrm{~min}$ ) to $315^{\circ} \mathrm{C}$ at $4^{\circ} \mathrm{C} / \mathrm{min}$, with total

142 run time of $100 \mathrm{~min}$. Steranes were monitored in MRM mode in the $386 \rightarrow 217$

143 transition. Samples were co-injected manually.

144 2.3.2. NMR

145 The NMR spectra were recorded on a Bruker Avance I $500 \mathrm{MHz}$ spectrometer (500

$146 \mathrm{MHz}$ for ${ }^{1} \mathrm{H} ; 125 \mathrm{MHz}$ for $\left.{ }^{13} \mathrm{C}\right)$. The chemical shifts are reported in parts per million

$147(\mathrm{ppm})$ relative to tetramethylsilane with the solvent used as internal standard $148\left(\mathrm{CHCl}_{3}: \delta^{1} \mathrm{H} 7.26 \mathrm{ppm} ; \mathrm{CDCl}_{3}: \delta^{13} \mathrm{C} 77.23 \mathrm{ppm}\right)$ and the coupling constants are 149 expressed in $\mathrm{Hz}$.

\section{3. Results and discussion}

151 3.1. Synthesis of 26-methyl $\alpha \alpha \alpha R$-cholestane 1

152 26-Methyl $\alpha \alpha \alpha R$-cholestane 1 was synthesized in 3 steps (Fig. 1a) starting from 153 26-hydroxy $\alpha \alpha \alpha R$-cholestane 2 (occurring as a $R+S$ epimeric mixture at C-25), a 154 compound previously prepared starting from stigmasterol following a 14-step 155 synthesis (Paulus, 1993). The first step of the present synthesis consisted of 156 oxidizing 2 into its related aldehyde 3 using PDC (Corey and Schmidt, 1979). For 


\section{Version non révisée}

157 the introduction of an additional carbon atom at C-26, the rhodium-catalyzed

158 methylenation of aldehydes described by Lebel and Paquet (2004) was used,

159 leading to the alkene 4 (Fig. 1a). This procedure involved $\mathrm{PPh}_{3}$, Wilkinson's

160 catalyst, and $\mathrm{TMSCHN}_{2}$ as the carbon source. A main difficulty was the low

161 amounts of substrate available $(7 \mathrm{mg})$ for this step, which required a significant

162 downscaling of the procedure described by Lebel and Paquet (2004). Since the

163 reaction cannot be performed using reagents in large excess, the synthesis on 2-3

$164 \mathrm{mg}$ aliquots of aldehyde 3 was performed in the presence of 6-7 $\mathrm{mg}$ of another

165 aldehyde acting as a load and which reacts in the same manner as 3. 16-oxo-

166 methylhexadecanoate obtained by PDC oxidation of commercial 16-hydroxy-

167 methylhexadecanoate was chosen as the load since this compound leads upon

168 methylenation to 16-methylene-methylhexadecanoate, a compound easily

169 separated from 4 by silica gel chromatography. Using this procedure, we

170 synthesized 26-methylene-cholestane 4 from aldehyde 3 in $62 \%$ yield. Finally, 26-

171 methyl $\alpha \alpha \alpha R$-cholestane 1 was obtained in almost quantitative yield by

172 hydrogenation of 4 using $\mathrm{PtO}_{2}$ as catalyst. In this synthesis, since the starting

173 product was present as a C-25 $R+S$ epimeric mixture, the synthetic intermediates

174 as well as the final compound were obtained as C-25 epimers which co-elute in GC

175 under the conditions used (see experimental), but can be partly distinguished upon

176 NMR analysis (presence of ${ }^{1} \mathrm{H}$ and ${ }^{13} \mathrm{C}$ splited signals indicating a $25 R / 25 S$ ratio of

177 ca. 1).

1783.2 Identification of the geochemical cryostanes as 26-methyl cholestane isomers

179 The identification of the geochemical cryostanes as 26-methyl cholestane isomers

180 relies on the fact that the mass spectrum of synthetic 26 -methyl $\alpha \alpha \alpha R$-cholestane

1811 (Fig. 1b) is identical to that of the last eluting geological cryostane isomer. In

182 addition, both compounds coelute in GC on two different columns (Fig. 1c). Given 


\section{Version non révisée}

183 the similarity with "classical" geological sterane distributions, the three-early

184 eluting geochemical isomers (Fig. 1c) most likely correspond to, respectively, $\alpha \alpha \alpha S$,

$185 \alpha \beta \beta R$ and $\alpha \beta \beta S$ isomers of $\mathbf{1}$. It is noteworthy that the first eluting cryostane 186 isomer coelutes with a minor synthetic $20 S$ isomer of $\mathbf{1}$ (< $3 \%$ related to $\mathbf{1}$ 187 determined by GC-MS). Its co-occurrence with 1 can be explained by the fact that 188 the synthesis of cholestan-26-ol 2 (Paulus, 1993) involved a short chain steroid 189 aldehyde intermediate 5 (Fig. 1a) likely to have isomerized to a small extent at the 190 C-20 (enol) position.

191 Biological sterols with the cryostane side-chain are not known. Sterols methylated

192 at C-26 and bearing additional alkylations at other positions (e.g. C-24) have 193 however been identified in living organisms, and seem to be restricted to some 194 demosponges (Giner, 1993). Most demosponges synthesize 26-methylsterols via 195 methylation of dietary sterols, and this capability was presumably present in the 196 last common ancestor of all Demospongiae. Based on molecular clock estimates, 197 demosponges may have emerged in the time interval 800 to $700 \mathrm{Ma}$, so a sponge 198 origin of cryostanes is conceivable and would represent the oldest molecular 199 evidence for animals (Brocks et al., 2016). However, other sources need to be 200 explored, including the large variety of eukaryotic protists that have a poorly 201 investigated lipidome, and the possibility of targeted microbial alteration of 202 sedimentary sterols.

\section{Acknowledgements}

204 E. Motsch (Université de Strasbourg) is thanked for the GC-MS analyses and M. 205 Coppe (Université de Strasbourg) for NMR measurements.

206 References

207 Brocks, J.J., Jarrett A.J.M., Sirantoine, E., Kenig, F., Moczydlowska, M., Porter, 208 S., Hope, J., 2016. Early sponges and toxic protists: possible sources of cryostane, 


\section{Version non révisée}

209

210

211

212

213

214

215

216

217

218

219

an age diagnostic biomarker antedating Sturtian Snowball Earth. Geobiology 14, 129-149.

Brocks, J.J., Jarrett, A.J.M., Sirantoine, E., Hallmann, C., Hoshino, Y., Liyanage, T., 2017. The rise of algae in Cryogenian oceans and the emergence of animals. Nature, doi:10.1038/nature23457.

Corey, E.J., Schmidt, G., 1979. Useful procedures for the oxidation of alcohols involving pyridinium dichromate in aprotic media. Tetrahedron Letters 5, 399-402. Giner, J.L., 1993. Biosynthesis of marine sterol side-chains. Chemical Reviews 93, 1735-1752.

Jarrett, A., Schinteie, R., Hope, J.M., Brocks, J.J., 2013. Micro-ablation, a new technique to remove drilling fluids and other contaminants from fragmented and fissile rock material. Organic Geochemistry 61, 57-65.

Lebel, H., Paquet, V., 2004. Rhodium-catalyzed methylenation of aldehydes. Journal of the American Chemical Society 126, 320-328.

Paulus, S., 1993. Biodégradation des stéranes pétroliers. PhD. Thesis, Université Louis Pasteur de Strasbourg, France.

\section{Figure caption}

Fig. 1. (a) Synthesis of 26-methyl $\alpha \alpha \alpha R$-cholestane 1 from 26-hydroxy $\alpha \alpha \alpha R$ cholestane 2 (i) $\mathrm{PDC}, \mathrm{CH}_{2} \mathrm{Cl}_{2}$, (ii) 16-oxo-methylhexadecanoate, $\mathrm{PrOH}, \mathrm{PPh}_{3}$, Wilkinson's catalyst, THF, (iii) $\mathrm{TMSCHN}_{2}, \mathrm{THF}$, (iv) $\mathrm{H}_{2}, \mathrm{PtO}_{2}$, EtOAc. (b) Mass spectrum (EI, $70 \mathrm{eV}$ ) of 26-methyl $\alpha \alpha \alpha R$-cholestane 1. (c) MRM chromatograms of $386 \rightarrow 217$ precursor-product transitions showing a co-injection experiment on a DB-5MS chromatographic column for the identification of cryostane. (I) Chuar Group sample 10J093 (outcrop, 1544 meters above base of Chuar Group); (II) coinjection of the above samples. 


\section{Version non révisée}
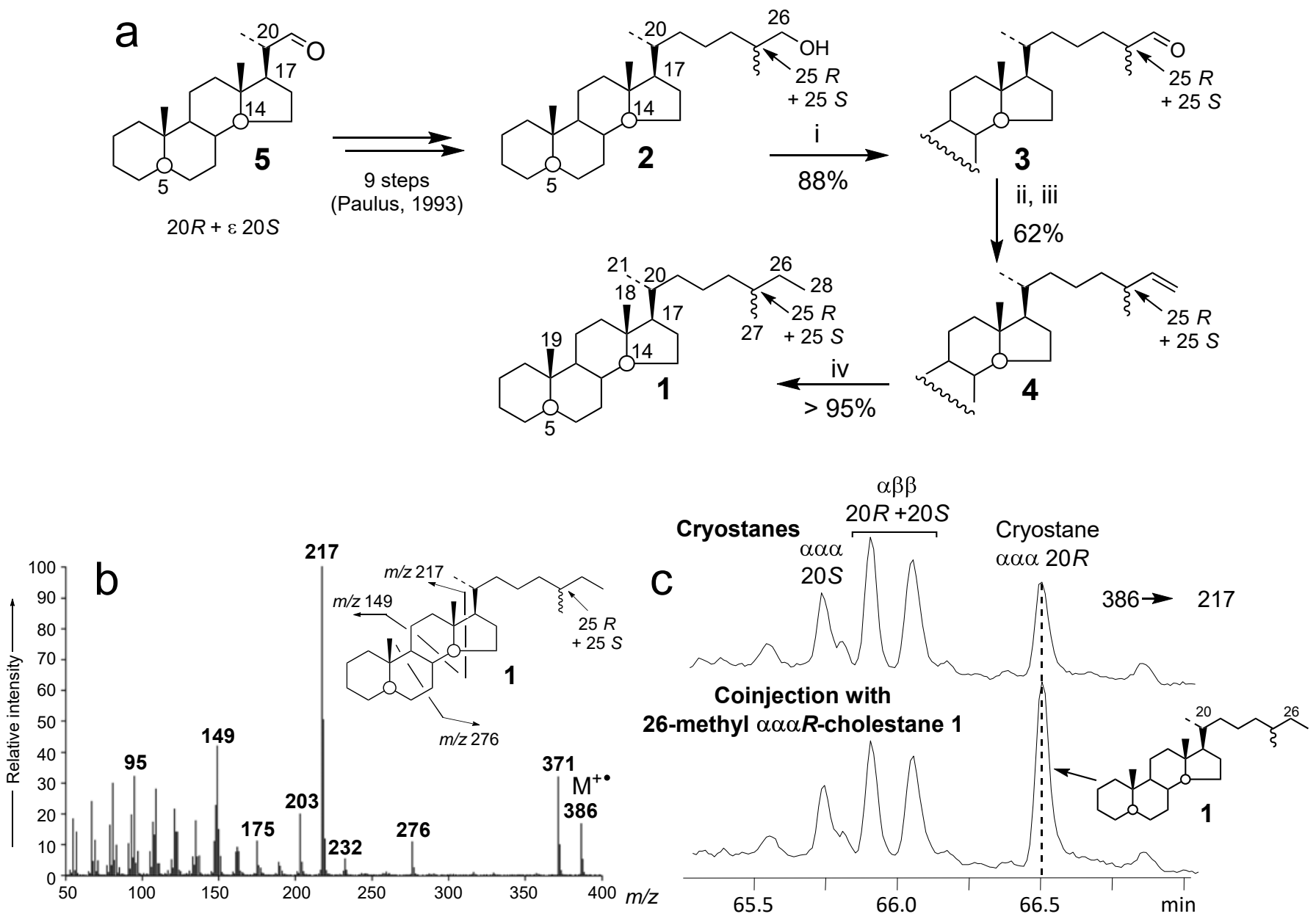

Figure 1 